\title{
A new ant species of the genus Tapinoma (Hymenoptera, Formicidae) from Saudi Arabia with a key to the Arabian species
}

\author{
Mostafa R. Sharaf ${ }^{1, \dagger}$, Abdulrahman S. Aldawood ${ }^{1, \neq}$, Magdi S. ElHawagry ${ }^{2, \S}$ \\ I Plant Protection Department, College of Food and Agriculture Sciences, King Saud University, Riyadh \\ 11451, PO Box 2460, Kingdom of Saudi Arabia 2 Basic Sciences Department, Community College, Al-Baha \\ University, Al-Baha, P. O. Box 1598, Kingdom of Saudi Arabia, Project: Survey and Classification of Agricul- \\ tural and Medical Insects in Al-Baha Province \\ † urn:lsid:zoobank.org:author:E2A42091-0680-4A5F-A28A-2AA4D2111BF3 \\ †urn:lsid:zoobank.org:author:477070A0-365F-4374-A48D-1C62F6BC15D1 \\ § urn:lsid:zoobank.org:author:1DBA1729-FB21-44F5-A704-1767A580BA2A \\ Corresponding author: Mostafa R. Sharaf(antsharaf@yahoo.com)
}

Academic editor: Brian Fisher | Received 3 May 2012 | Accepted 17 July 2012 | Published 30 July 2012

urn:lsid:zoobank.org:pub:AF8066D8-733F-401E-811D-E8AF4595C0A3

Citation: Sharaf MR, Aldawood AS, ElHawagry MS (2012) A new ant species of the genus Tapinoma (Hymenoptera, Formicidae) from Saudi Arabia with a key to the Arabian species. ZooKeys 212: 35-43. doi: 10.3897/zookeys.212.3325

\begin{abstract}
Tapinoma wilsoni sp. n. is described and illustrated from Saudi Arabia based on the worker caste collected from Al Baha, Saudi Arabia. It closely resembles Tapinoma lugubre Santschi 1917, from Zimbabwe in body measurements but can be distinguished from the latter species by the yellowish brown color; the yellowish pubescence, the two pairs of hairs present on the anterior part of the head; and the distinctly concave anterior clypeal margin. Biological and ecological notes of the new species are presented. An identification key to the workers of the Arabian species of the genus Tapinoma is given.
\end{abstract}

\section{Keywords}

Dolichoderinae, Kingdom of Saudi Arabia, Middle East, new species, Palaearctic, Al Sarawat Mountains

\section{Introduction}

The genus Tapinoma was established by Foerster (1850), with the type-species T. collina Foerster. The genus currently comprises 126 described species and subspecies (Bolton et

Copyright Mostafa R. Sharaf et al. This is an open access article distributed under the terms of the Creative Commons Attribution License 3.0 (CC-BY), which permits unrestricted use, distribution, and reproduction in any medium, provided the original author and source are credited. 
al. 2007) distributed worldwide in tropical and temperate regions (Brown 2000). Members of this genus are generalized foragers (Brown 2000), nesting in a wide variety of habitats, ranging from grasslands, open fields, woodlands, to inside buildings. The majority of species nest in the ground under objects such as stones or tree logs, other species build nests under bark of logs and stumps, in plant cavities, insect galls or refuse piles (Smith, 1965). Tapinoma simrothi Krausse in Saudi Arabia was observed nesting in a decaying carpet, among roots of graminae plants and attending unidentified mealybugs, and also coexisting with Solenopsis saudiensis Sharaf \& Aldawood (Sharaf and Aldawood 2011).

Terminology used to characterize Tapinoma follows Bolton (1973, 1994): Mandibles with two or three large apical teeth, followed by a row of denticles; palp formula 6,4; clypeus with or without median anterior border emarginated; antennae 12-segmented; propodeum unarmed or rarely with a pair of blunt tubercles; petiole reduced or vestigial, overhung by the first gastral segment and not visible in dorsal view; only four gastral segments visible in dorsal view; fifth tergite reflexed below the fourth, visible in ventral view where it forms a transverse plate abutting the fifth sternite; the anal and associated orifices are thus situated ventrally.

Only two named species of Tapinoma have been recorded from countries occupying the Arabian Peninsula, T. melanocephalum (Fabricius) from Saudi Arabia and Oman (Collingwood 1985), UAE (Collingwood et al. 1997, Collingwood et al. 2011),Yemen (Collingwood and Agosti 1996, Collingwood and Van Harten 2001) and Socotra Archipelago (Collingwood et al. 2004); T. simrothi from Saudi Arabia (Collingwood 1985), Kuwait (Collingwood 1985, Collingwood and Agosti 1996), UAE (Collingwood et al. 1997, Collingwood et al. 2011), Qatar (Sharaf and Abdeldayem, in preparation), Oman (Collingwood 1988) and Yemen (Collingwood and Agosti 1996).

In the present study, a new species of the genus Tapinoma is described from Saudi Arabia and a key to the known Arabian species is given.

\section{Materials and methods}

Measurements and indices follow Bolton (2007).

\section{Measurements}

Total Length (TL): The total outstretched length of the ant from the mandibular apex to the gastral apex.

Head Length (HL): The length of the head capsule, excluding the mandibles; measured in full-face view in a straight line from the mid-point of the anterior clypeal margin to the mid-point of the posterior margin. In species where one or both of these margins are concave, the measurement is taken from the mid-point of a transverse line that spans the apices of the projecting portions.

Head Width (HW): The maximum width of the head behind the eyes, measured in full-face view. 
Scape Length (SL): The maximum straight-line length of the scape, excluding the basal constriction or neck that occurs just distal of the condylar bulb.

Pronotal Width (PW): The maximum width of the pronotum in dorsal view.

Weber's length of Mesosoma (WL): The diagonal length of the mesosoma in profile, from the most anterior point of the pronotum to the posterior basal angle of the metapleuron.

All measurements are expressed in millimeters.

\section{Indices}

Cephalic Index (CI): HW divided by HL, $\times 100$.

Dorsal Thoracic Index (DTI): In dorsal view, the length from the mid-point of the anterior pronotal margin to the midpoint of the metanotal groove, divided by PW, $\times 100$.

Eye Position Index (EPI): In full-face view the straight-line length (parallel to the long axis of the head) from the most anterior point of the eye to the anterior clypeal margin, divided by the straight-line length from the most posterior point of the eye to the posterior margin, $\times 100$.

Ocular Index (OI): Maximum diameter of eye divided by HW, $\times 100$.

Scape Index (SI): SL divided by HW, × 100.

\section{Illustrations}

Specimens were photographed by using Digital color images that were created using a Leica DFC 425 camera in combination with the Leica Application Suite software (version 3.8). All images presented are available online at AntWeb (http://www.antweb.org).

\section{Depositories of type specimens}

BMNH Natural History Museum, London, United Kingdom.

CASC California Academy of Sciences Collection, San Francisco, California, USA.

KSMA King Saud Museum of Arthropods, King Saud University, Riyadh, Kingdom of Saudi Arabia.

MCZC Museum of Comparative Zoology, Cambridge, MA, USA.

MHNG Muséum d'Histoire Naturelle, Geneva, Switzerland.

NHMB Naturhistorisches Museum, Basel, Switzerland.

WMLC World Museum Liverpool, Liverpool, United Kingdom.

SEMC Division of Entomology (Snow Entomological Collections), University of Kansas Natural History Museum, Lawrence, Kansas, USA. 


\section{Results}

Tapinoma wilsoni Sharaf \& Aldawood, sp. $\mathrm{n}$. urn:Isid:zoobank.org:act:2680E437-3109-4F74-B21D-5A99A8ABB8C0 http://species-id.net/wiki/Tapinoma_wilsoni

Figs $1-3$

Holotype worker. Saudi Arabia, Al Baha, Al Sarawat Mountains, Dhi Ayn Archaeological Village, $19.92972^{\circ} \mathrm{N}, 41.44278^{\circ} \mathrm{E}, 741 \mathrm{~m}, 15 . v .2011$ (M. R. Sharaf Leg.); deposited in the King Saud Museum of Arthropods, College of Food and Agriculture Sciences, King Saud University, Riyadh, Kingdom of Saudi Arabia.

Paratype workers. 29 workers, same locality as holotype, deposited as follows: 1 in MHNG (Dr Bernhard Merz); 1 in NHMB (Mrs. Isabelle Zürcher-Pfander); 1 in CASC (Dr Brian Fisher); 1 in MCZC (Dr Stefan Cover); 2 in WMLC (Tony Hunter), 1 in BMNH (Mr. Barry Bolton); 1 in SEMC (Prof. Michael S. Engel) the remaining specimens in KSMA (M. R. Sharaf).

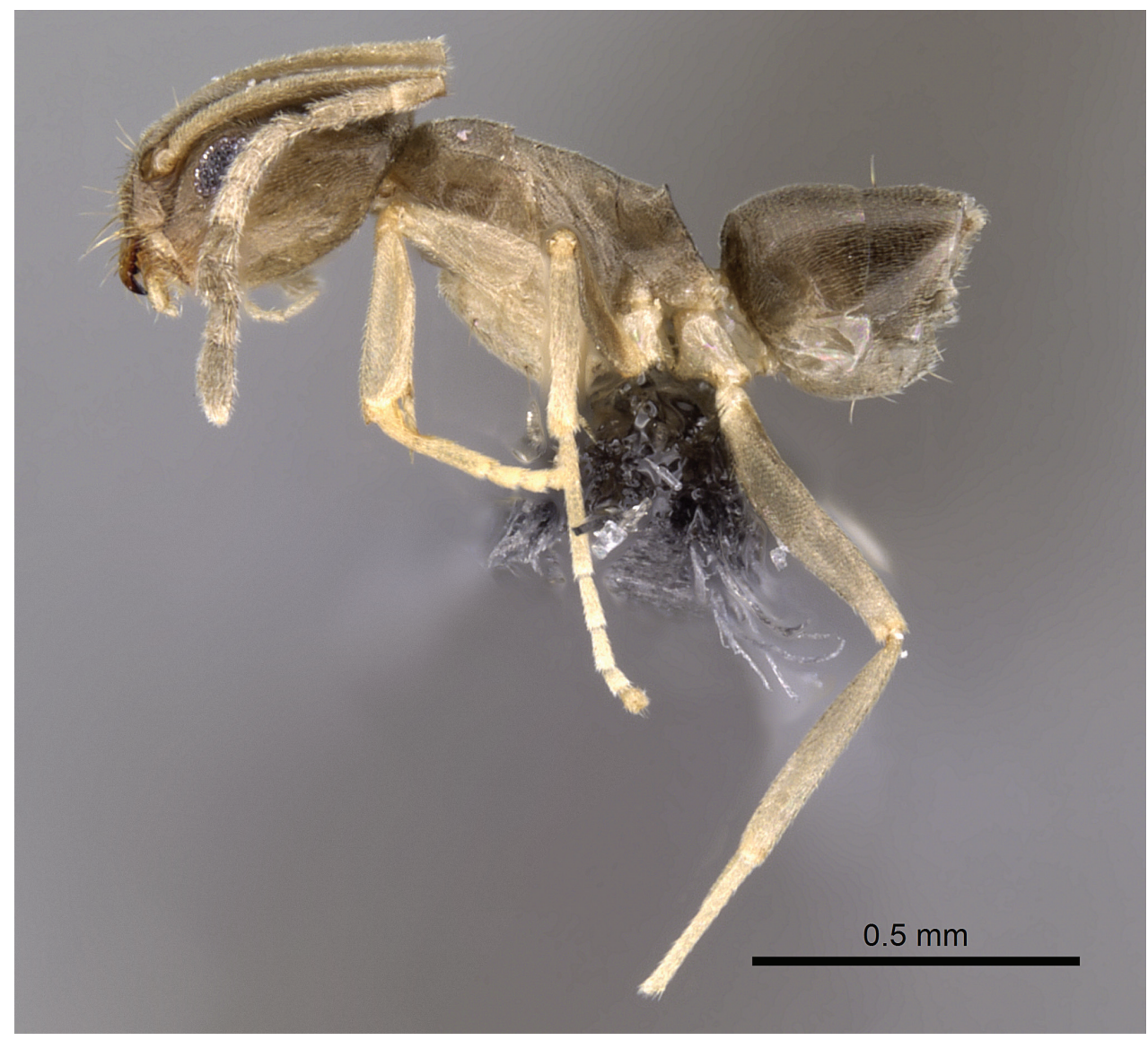

Figure I. Lateral view of paratype worker of Tapinoma wilsoni sp. n. (CASENT0263919) 


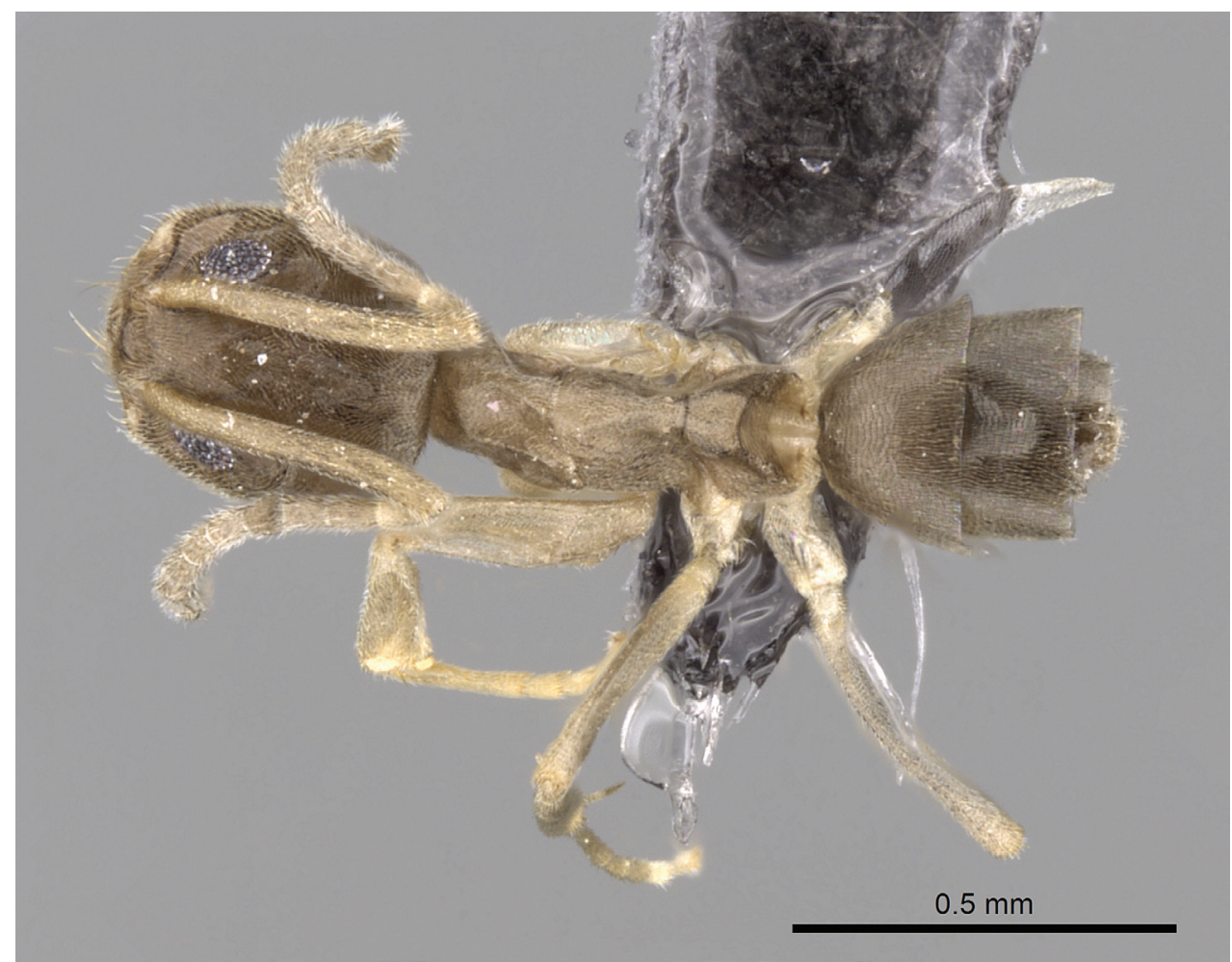

Figure 2. Dorsal view of paratype worker of Tapinoma wilsoni sp. n. (CASENT0263919)

Additional paratype workers. Saudi Arabia, Al Baha, Dhi Ayn Archaeological Village, $19.92976^{\circ} \mathrm{N}, 41.44187^{\circ} \mathrm{E} \pm 50 \mathrm{~m}, 23 . \mathrm{ix} .2011$ (B.L. Fisher Leg.) 4 deposited in CASC.

Measurements. Holotype: TL: 1.84, HL: 0.51, HW: 0.41, SL: 0.46, PW: 0.29, WL: 0.56, EL: 0.11. Indices: CI: 80, SI: 112, OI: 27, EPI: 71, DTI: 134.

Paratypes: TL: 1.56-1.84, HL: 0.49-0.53, HW: 0.36-0.42, SL: 0.35-0.51, PW: 0.25-0.31, WL: 0.49-0.63, EL: 0.09-0.14. Indices: CI: 73-84, SI: 105-133, OI: 2233, EPI: 67-82, DTI: 114-145 (11 measured).

Description of worker. Head distinctly longer than broad with feebly convex posterior margin and sides; anterior clypeal margin broadly and distinctly concave; scapes, in full-face view, surpassing posterior margin of head by about $1 / 6$ of its length; all funicular segments clearly longer than broad; eyes relatively large (OI 2233) with 8 ommatidia in the longest row; mandibles large, armed with two distinct apical teeth followed by two smaller teeth, the third tooth being smaller than the fourth; the remaining masticatory margin equipped with several indistinct and tiny denticles; mandibles with several long yellow hairs; head pilosity a fine, whitish, appressed pubescence; promesonotum in profile straight or feebly convex; metanotal groove indistinct; propodeum in profile with the transition from dorsum to declivity sharply defined, the declivity concave and the angle with a raised apex; body pilosity restricted to two pairs of setae on dorsum of head, located close to antennal 


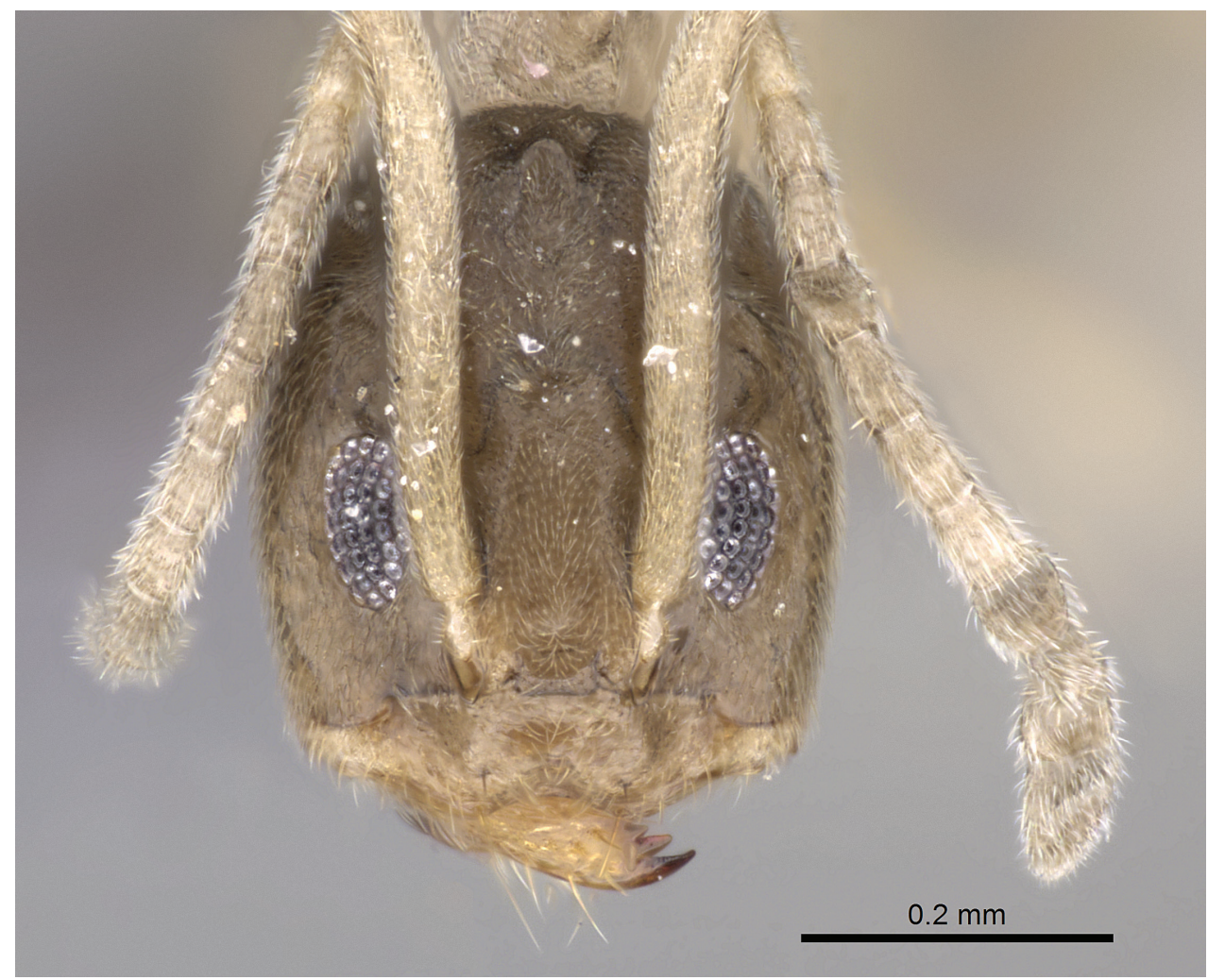

Figure 3. Frontal view of paratype worker of Tapinoma wilsoni sp. n. (CASENT0263919)

insertions and at the level of the anterior eye margin, none on mesosoma, one pair on second and third gastral tergites (absent in some individuals), apex of gaster with several pairs of long hairs; body very finely and densely shagreenate; mesosoma dull, head and gaster more or less shining. Color brownish yellow or yellowish with very faint brownish tint on dorsum of head, appendages clear yellow.

Etymology. A patronymic name honors Prof. Edward O. Wilson in recognition of his valuable contribution to the science of myrmecology over several decades.

The following key separates the members of the genus Tapinoma hitherto known from the Arabian Peninsula, including T. wilsoni.

\section{Key to the Arabian species of the genus Tapinoma}

1 Larger species, TL more than $2.0 \mathrm{~mm}$; color darker, uniformly blackish brown or black. simrothi Krausse

- $\quad$ Smaller species, TL less than $2.0 \mathrm{~mm}$; uniformly pale yellow or brownish yellow, or at least with gaster yellow 
Propodeum in profile with the transition from dorsum to declivity sharply defined, the declivity concave and the angle with a raised apex; brownish yellow or yellowish with very faint brownish tint on head dorsum, appendages clear yellow wilsoni sp. $\mathrm{n}$.

- $\quad$ Propodeum in profile with the transition from dorsum to declivity no more than a rounded angle; head and mesosoma dark yellowish-brown, gaster yellow...... melanocephalum (Fabricius)

\section{Discussion}

Tapinoma wilsoni appears most similar to T. lugubre Santschi, 1917, which was described from Zimbabwe. The two species are similar in size (TL 1.50-1.80) and both have the propodeum in profile with the transition from dorsum to declivity sharply defined, the declivity concave, and the angle with a raised apex. Tapinoma wilsoni can be easily separated from T. lugubre by the following characters: color brownish yellow or yellowish with fine brownish tint on head dorsum, appendages clear yellow, while T. lugubre is much darker brown or dull yellowish black, with occiput and gaster blackish. In T. wilsoni, the scape surpasses the posterior margin of head by about $1 / 6$ of its length, whereas in T. lugubre, the scape surpasses the posterior margin of head by about $1 / 4$ not similar in formatting to $1 / 6$ in the above line!. In addition, T. wilsoni has the anterior clypeal margin distinctly concave, while in T. lugubre the middle of the anterior clypeal margin is shallowly concave. Moreover, T. wilsoni has two pairs of setae on the dorsum of the head, one close to antennal insertions and the other at the level of the anterior margin of eyes and several pairs on clypeus; whereas T. lugubre lacks hairs on the dorsum of the head. T. wilsoni can be easily separated from other Arabian species by the concave propodeal declivity and the well-defined angle between dorsum of propodeum and declivity.

Habitat and biology. The specimens of $T$. wilsoni were found foraging on the ground, and coexisting with the ant species Carebara abuhurayri Sharaf \& Aldawood, Tetramorium sericeiventre Emery, Pheidole minuscule Bernard, Pheidole sp., Monomorium destructor (Jerdon), Monomorium exiguum (Forel), Monomorium sp., and Crematogaster sp. The type locality (Fig. 4) of this new species is a semi isolated area which is completely surrounded by high mountains and largely under banana cultivation. The new species was collected at the base of banana trees. Due to continuous irrigation of the banana plantations, the soil is moist throughout the year. The type locality still has a diversity of native plants as well as many other cultivated species, especially date palm, Ficus trees, alfalfa and some lemon trees. Numerous small streams drain this area.

Tapinoma wilsoni is the first new species to be described in the genus since Collingwood's (1985) review of the Arabian ant fauna. We believe that the Mountains of Al Sarwat and Asir (southwestern region of the Arabian Peninsula) may yield a wealth of undescribed ant species. 


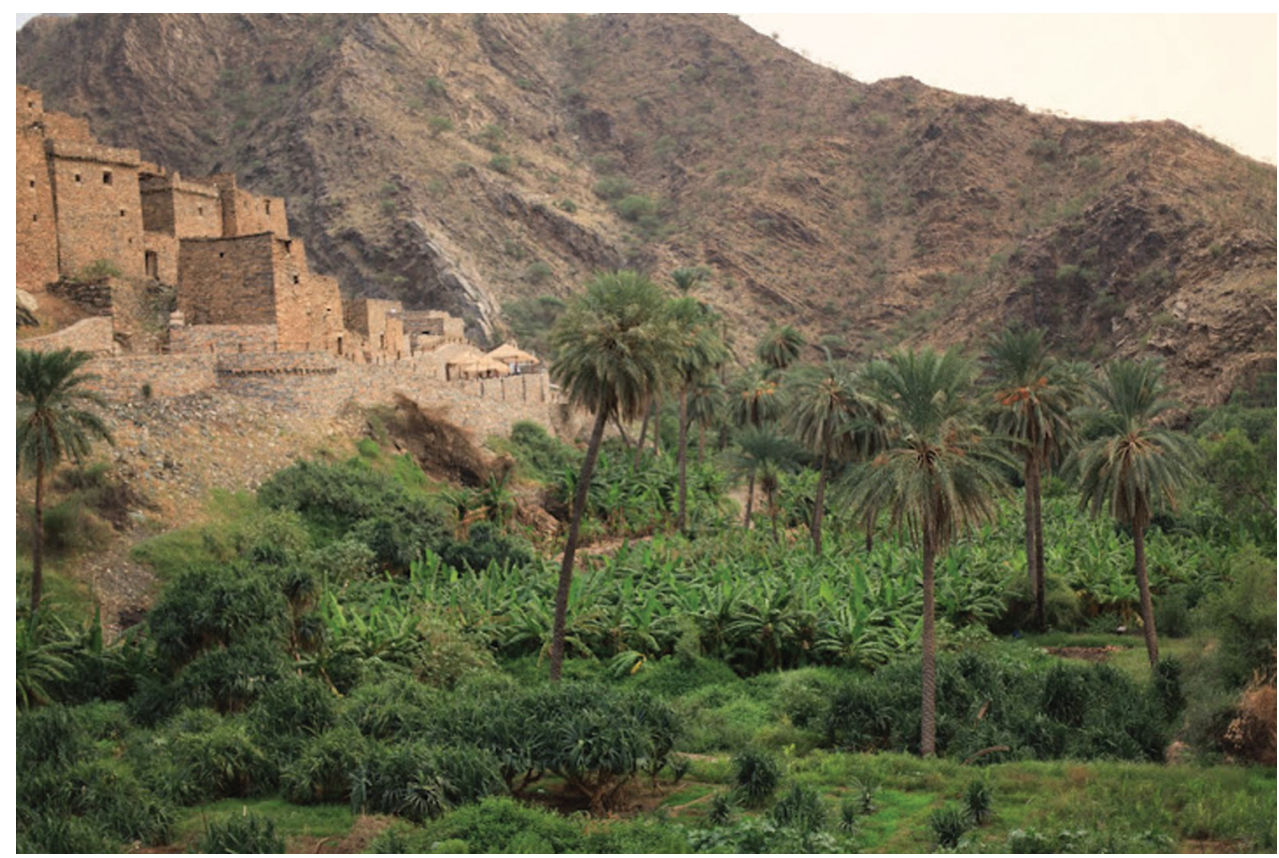

Figure 4. Type Locality Dhi Ayn Archaeological Village, Al-Baha Province, Saudi Arabia. (Brian Fisher photo)

\section{Acknowledgments}

This project was supported by King Saud University, Deanship of Scientific research, College of Food and Agriculture Sciences, Research Center. The authors are most grateful to Barry Bolton and Boris Kondratieff who very kindly edited the manuscript and provided useful suggestions. Special thanks to Brian Fisher (CAS and visiting professor, King Saud University) and Estella Ortega, (CAS), San Francisco, U.S.A., for cooperating in imaging the new species, Antweb. We are indebted to Brian Fisher and two anonymous reviewers for valuable comments. The first author thanks Mohammed Metwally and Hoda Samir for encouragements.

\section{References}

Bolton B (1973) The ant genera of West Africa: a synonymic synopsis with keys. Bulletin of the British Museum (Natural History) (Entomology) 27: 317-368.

Bolton B (1994) Identification Guide to the Ant Genera of the World. Cambridge, Mass, 222 pp. Bolton B (2007) Taxonomy of the Dolichoderine ant genus Technomyrmex Mayr (Hymenoptera: Formicidae) based on the worker caste. Contributions of the American Entomological Institute 35(1): 1-150.

Bolton B, Alpert G, Ward PS, Naskrecki P (2007) Bolton's Catalogue of the Ants of the World: 1758-2005. Compact Disc Edition, Harvard University Press. 
Brown WL JR (2000) Diversity of ants. In: Agosti D, Majer J, Alonso E, Schultz TR (Eds) Ants: standard methods for measuring and monitoring biodiversity. Biological diversity hand book series. Smithsonian Institution Press, Washington and London, 280 pp.

Collingwood CA (1985) Hymenoptera: Family Formicidae of Saudi Arabia. Fauna of Saudi Arabia 7: 230-301.

Collingwood CA (1988) The ants (Hymenoptera, Formicidae) of the Wahiba Sands, Oman. Journal of Oman Studies Special Report 3: 361-362.

Collingwood CA, Agosti D (1996) Formicidae (Insecta: Hymenoptera) of Saudi Arabia (part 2). Fauna of Saudi Arabia 15: 300-385.

Collingwood CA, Tigar BJ, Agosti D (1997) Introduced ants in the United Arab Emirates. Journal of Arid Environments 37: 505-512. doi: 10.1006/jare.1997.0309

Collingwood CA, van Harten A (2001) Additions to the ant fauna of Yemen (Hymenoptera: Formicidae). Esperiana 8: 559-568.

Collingwood CA, Pohl H, Güsten R, Wranik W, van Harten A (2004) The ants (Insecta: Hymenoptera: Formicidae) of the Socotra Archipelago. Fauna of Arabia 20: 473-495.

Collingwood CA, Agosti D, Sharaf MR, van Harten A (2011) Order Hymenoptera, family Formicidae. Arthropod Fauna of the UAE 4: 405-474.

Foerster A (1850) Hymenopterologische Studien 1. Formicariae, Aachen, 74 pp.

Sharaf MR, Aldawood AS (2011) First occurrence of Solenopsis Westwood 1840 (Hymenoptera: Formicidae), in the Kingdom of Saudi Arabia, with description of a new species $S$. saudiensis sp. n. Annals' de la Société Entomologique de France 47(3/4): 474-479.

Smith MR (1965) House-infesting ants of the eastern United States. Their recognition, biology, and economic importance. United States Department Agriculture Technology Bulletin 1326: 1-105. 